\title{
Mesoporous Silica-Supported Sulfonyldiamine Ligand for Microwave-Assisted Transfer Hydrogenation
}

\author{
Shaheen M. Sarkar, ${ }^{1}$ Md. Eaqub Ali, ${ }^{2}$ Md. Shaharul Islam, ${ }^{1}$ Md. Lutfor Rahman, \\ S. S. Rashid, ${ }^{1}$ M. R. Karim, ${ }^{1}$ and Mashitah Mohd Yusoff ${ }^{1}$ \\ ${ }^{1}$ Faculty of Industrial Sciences and Technology, Universiti Malaysia Pahang, 26300 Gambang, Kuantan, Malaysia \\ ${ }^{2}$ Nanotechnology and Catalysis Research Centre (NanoCat), University of Malaya, Level 3, Block A, IPS Building, \\ 50603 Kuala Lumpur, Malaysia
}

Correspondence should be addressed to Md. Eaqub Ali; eaqubali@gmail.com

Received 21 July 2014; Accepted 26 August 2014

Academic Editor: Wei-Chun Chen

Copyright (C) 2015 Shaheen M. Sarkar et al. This is an open access article distributed under the Creative Commons Attribution License, which permits unrestricted use, distribution, and reproduction in any medium, provided the original work is properly cited.

$\mathrm{N}$-Sulfonyl-1,2-diamine ligands, derived from 1,2-diaminocyclohexane and 1,2-diaminopropane, were immobilized onto mesoporous SBA-15 silica. The SBA-15-supported sulfonyldiamine-Ru complex was prepared in situ under microwave heating at $60 \mathrm{~W}$ for $3 \mathrm{~min}$. The prepared sulfonyldiamine-Ru complex was used as an efficient catalyst for the transfer hydrogenation of ketones to the corresponding secondary alcohols. The heterogeneous complex showed extremely high catalytic activity with $99 \%$ conversion rate under microwave heating condition. The complexes were regenerated by simple filtration and reused two times without significant loss of activity.

\section{Introduction}

Catalytic transfer hydrogenation of ketones and imines is an attractive method for the preparation of alcohols or amines [1-3]. Several homogeneous catalysts have been proposed for the transfer hydrogenation reactions [4-10]. However, the separation and recycling of homogeneous catalysts are complicated. Therefore, attempts were made to attach the catalyst to an insoluble support to improve the handling and separation of catalyst from the reaction mixture and also its recycling [11-13]. Several homogeneous catalysts were immobilized on supports such as dendritic polymers [1416], silica [17], polystyrene [18, 19], biphasic catalysis [20], and Al-SBA-15 materials [21]. However, despite having highly ordered mesoporous structures with uniform pore diameter $(6 \sim 7 \mathrm{~nm})$ and high surface area, very few catalysts were tested on silica SBA-15 matrix [22-24].

Due to well-known silicon chemistry, various organic groups could be robustly anchored in the surface of SBA15 silica. This strategy would offer practical advantages such as simplified separation, easy recovery, and poten- tial reuse of catalyst over traditional solution-phase chemistry [25]. Our interest in recyclable immobilized catalysts led us to prepare mesoporous SBA-15-supported $N$-sulfonyl-1,2-diaminocyclohexane and 1,2-diaminopropane ligands and their $\mathrm{Ru}$ complexes for transfer hydrogenation reaction. Since heterogeneous catalysis typically requires long reaction time, we used here microwave-assisted reactions which occur much faster than conventional heating reactions [26-28]. To the best of our knowledge, we described here SBA-15-supported $N$-sulfonyl-1,2-diaminocyclohexane and 1,2-diaminopropane ligands and their $\mathrm{Ru}$ complexes for the heterogeneous transfer hydrogenation of ketones under microwave irradiation conditions for the first time.

\section{Experimental}

2.1. Preparation of the Mesoporous SBA-15 Silica. Mesoporous silica SBA-15 was synthesized according to Zhao et al. [24]. Briefly, $4 \mathrm{~g}$ of Pluronic P123 was dissolved in $30 \mathrm{~g}$ of water and $120 \mathrm{~g}$ of $2 \mathrm{M} \mathrm{HCI}$ solution at room temperature under 
vigorous stirring. Then $8.5 \mathrm{~g}$ of TEOS was added into that solution under stirring. The reaction mixture was maintained at room temperature for $10-12 \mathrm{~h}$ and then at $60^{\circ} \mathrm{C}$ for $48 \mathrm{~h}$ and then kept at $120^{\circ} \mathrm{C}$ for $24 \mathrm{~h}$ under static conditions in a Teflonlined autoclave to generate materials with uniform pore diameter from 4 to $10 \mathrm{~nm}$. The solid product was recovered and washed with DI water.

2.2. Preparation of the Trimethoxysilated N-Sulfonyl-1,2diamines 2. To a solution of 2-(4-chlorosulfonylphenyl)ethyltrimethoxysilane $(400 \mathrm{mg}, 1.23 \mathrm{mmoL})$ in $\mathrm{CH}_{2} \mathrm{Cl}_{2}(10 \mathrm{~mL})$ was slowly added a solution of 1,2-diaminocyclohexane la (140 mg, $1.23 \mathrm{mmoL}$ ) and triethylamine (124 mg, $1.23 \mathrm{mmoL})$ in $\mathrm{CH}_{2} \mathrm{Cl}_{2}(7 \mathrm{~mL})$ at $-10^{\circ} \mathrm{C}$. The reaction mixture was allowed to warm at room temperature and stirred for $2 \mathrm{~h}$. The mixture was diluted with $\mathrm{CH}_{2} \mathrm{Cl}_{2}$ and washed with cold water. The organic layer was dried over $\mathrm{MgSO}_{4}$ and concentrated under reduced pressure. The crude product was purified by flash chromatography to give trimethoxysilylated $N$-sulfonyl-1,2diaminocyclohexane $\mathbf{2 a}$ in $\mathbf{8 5 \%}$ yield. Compound $\mathbf{2 b}$ was similarly prepared from 1,2-diaminopropane $\mathbf{l b}$ in $78 \%$ yield.

2.3. Preparation of the SBA-15-Supported Sulfonyldiamines 3. SBA-15 silica ( $1.0 \mathrm{~g})$ was added to a solution of compound 2a $(110 \mathrm{mg}, 0.27 \mathrm{mmoL})$ in toluene $(15 \mathrm{~mL})$ and the mixture was refluxed for $18 \mathrm{~h}$. After filtration, the powder was washed several times with methylene chloride and dried under vacuum at $70^{\circ} \mathrm{C}$ to give SBA-15-supported $N$-sulfonyldiamine 3a. Weight gain showed that $0.18 \mathrm{mmoL} / \mathrm{g}$ of compound $2 \mathrm{a}$ was grafted in $1.0 \mathrm{~g}$ of SBA-15-silica 3a. The SBA-15-supported $N$-sulfonyldiamine $\mathbf{3} \mathbf{b}$ was also prepared from compound $\mathbf{2} \mathbf{b}$ by the same procedure. Weight gain showed that $0.15 \mathrm{mmoL} / \mathrm{g}$ of compound $\mathbf{2} \mathbf{b}$ was anchored in $1.0 \mathrm{~g}$ of the SBA-15 silica $\mathbf{3 b}$.

\subsection{Characterization of the SBA-15-Supported Ligand 3.} Mesostructures of the synthesized materials were identified by powder X-ray diffractions (XRD). The XRD patterns were obtained by using a Rigaku Multiflex diffractometer with a monochromated high-intensity $\mathrm{CuK}_{\alpha}$ radiation $(\lambda=1.54 \AA)$. Scanning was performed under ambient conditions over the $2 \theta$ region of $0.6-4.5^{\circ}$ at the rate of $0.1^{\circ} / \mathrm{min}(20 \mathrm{kV}, 10 \mathrm{~mA})$. The XRD diffractograms showed three peaks at 100, 110, and 200 which revealed that the synthesized structure was cubic $\operatorname{Im} 3 \mathrm{~m}$. The transmission electron microscopy (TEM) was performed with a FEI Tecnai $G^{2}$ microscope operated at $200 \mathrm{kV}$. The TEM sample was prepared by placing a few drops of SBA-15 powder dispersed in ethanol on a carbon grid and allowed to dry for $5 \mathrm{~min}$ before TEM analysis. Some of the samples, which have big particles, were crushed by submerging them in liquid nitrogen followed by mechanical grinding in a mortar prior to acetone dispersion. The nitrogen adsorption-desorption measurements were performed at $-196^{\circ} \mathrm{C}$ on a Micromeritics ASAP 2020 surface area and porosity analyzer. Approximately, $0.5 \mathrm{~g}$ of SBA- 15 was degassed at $300^{\circ} \mathrm{C}$ for $9 \mathrm{~h}$ before the measurement. The surface area determination was performed by the BrunauerEmmett-Teller (BET) method [29] over the relative pressure $\left(P / P_{0}\right)$ range of $0.05-0.2$, and the pore-size distribution was determined using the Broekhoff-de Boer (BdB) method [30] applied to the adsorption branch. Finally, the total pore volume was calculated from the amount of adsorbed $\mathrm{N}_{2}$ at $P / P_{0}=0.99$, and the microporous volume was determined using the $t$-plot method.

2.5. Transfer Hydrogenation of Ketones under Microwave Irradiation. SBA-15-supported ligand $3(0.03 \mathrm{mmoL})$ was suspended in water $(2 \mathrm{~mL})$ and heated with $\left[\mathrm{Ru}(p \text {-cymene }) \mathrm{Cl}_{2}\right]_{2}$ $(6.12 \mathrm{mg}, 0.01 \mathrm{mmoL})$ for $3 \mathrm{~min}$ under MW $(60 \mathrm{~W})$. Ketone $(1 \mathrm{mmoL})$ and $\mathrm{HCO}_{2} \mathrm{Na}(340 \mathrm{mg}, 5 \mathrm{mmoL})$ were added to the solution and heated under MW $(40 \sim 60 \mathrm{~W})$ for short reaction time (Table 2 ) and the conversion was monitored by GC analysis. After completion of the reaction (GC analysis), the mixture was cooled at room temperature and diluted with diethyl ether. The organic layer was washed by brine and dried over $\mathrm{MgSO}_{4}$. The crude product was purified by short column chromatography.

\section{Results and Discussion}

Preparation of the SBA-15-supported $N$-sulfonyldiamine 3a and $N$-sulfonyldiamine $\mathbf{3 b}$ was performed in a two-step reaction shown in Scheme 1. Reaction of 1,2-diaminocyclohexane with 2-(4-chlorosulfonylphenyl)ethyltrimethoxysilane produced trimethylsilylated $N$-sulfonyl-1,2-diaminocyclohexane 2a with a yield of $85 \%$. Subsequent condensation of $\mathbf{2 a}$ with the surface silanols of SBA-15 silica support in refluxing toluene yielded immobilized $N$-sulfonyldiamine SBA-15 silica 3a (loading ratio: $0.18 \mathrm{mmoL} / \mathrm{g}$ ).

Similarly, immobilized $N$-sulfonyldiamine $\mathbf{3 b}$ (loading ratio: $0.15 \mathrm{mmoL} / \mathrm{g}$ ) was obtained from 1,2-diaminopropane. The loading ratios for the SBA-15-supported $N$ sulfonyldiamines were determined by measuring weight gain. The TEM images are obtained after the modification of the parent SBA-15 silica which showed that the hexagonal symmetry of the pore arrays is conserved after immobilization of organic moiety onto the SBA-15 silica (Figure 1). The hexagonal symmetry of the pore arrays also appeared in XRD analysis (Figure 2).

The BET surface area and pore diameter of the SBA-15 silica were measured before and after immobilizing the ligand (Table 1 and Figure 3). It was clearly observed that both the surface area and pore diameter were significantly decreased following the modifications.

The SBA-15-supported Ru(II) complexes were prepared in situ by $\mathrm{MW}$-assisted heating of a mixture of $[\mathrm{Ru}(p-$ cymene) $\left.\mathrm{Cl}_{2}\right]_{2}$ and the supported ligand 3 in $\mathrm{H}_{2} \mathrm{O}$ at $1: 3$ ratio. With the SBA-15-supported $N$-sulfonyldiamine ligand 3a, we first performed microwave-assisted transfer hydrogenation of acetophenone $(1 \mathrm{mmoL})$ as a model substrate using $[\mathrm{Ru}(p$ cymene $\left.) \mathrm{Cl}_{2}\right]_{2}(0.01 \mathrm{mmoL})$ and $0.03 \mathrm{mmoL}$ of ligand $3 \mathbf{a}$ in aqueous $\mathrm{HCO}_{2} \mathrm{Na}$ under $80 \mathrm{~W}$ microwave irradiation. The catalyst showed high activity and provided corresponding alcohol in a quantitative yield within 30 min reaction time (Table 2, entry 1). Surprisingly, the catalyst showed outstanding catalytic activity to give the corresponding alcohol when the microwave power decreased to $60 \mathrm{~W}$ (entries 2, 
TABLE 1: Structural information of the SBA-15-supported sulfonyldiamine 3.

\begin{tabular}{lcccc}
\hline Sample & Surface area & Pore diameter & Pore volume & Functional group \\
\hline SBA-15 & $750 \mathrm{~m}^{2} / \mathrm{g}$ & $8.33 \mathrm{~nm}$ & $0.83 \mathrm{~cm}^{3} / \mathrm{g}$ & - \\
3a & $481 \mathrm{~m}^{2} / \mathrm{g}$ & $7.25 \mathrm{~nm}$ & $0.39 \mathrm{~cm}^{3} / \mathrm{g}$ & $0.18 \mathrm{mmoL} / \mathrm{g}$ \\
3b & $504 \mathrm{~m}^{2} / \mathrm{g}$ & $7.51 \mathrm{~nm}$ & $0.45 \mathrm{~cm}^{3} / \mathrm{g}$ & $0.15 \mathrm{mmoL} / \mathrm{g}$ \\
\hline
\end{tabular}

TABLE 2: Microwave-assisted transfer hydrogenation in the presence of $\mathbf{3}^{\mathrm{a}}$.

\begin{tabular}{|c|c|c|c|c|c|}
\hline Entry & Ketone & Ligand & Power (W) & $\begin{array}{l}\text { Time } \\
(\mathrm{min})\end{array}$ & Conv. $(\%)^{b}$ \\
\hline 1 & & $3 a$ & 80 & 30 & 100 \\
\hline 2 & & $3 a$ & 60 & 30 & $99(94)^{c}$ \\
\hline 3 & & $3 a$ & 60 & 30 & $95^{\mathrm{d}}$ \\
\hline 4 & & $3 a$ & 50 & 30 & $96(92)^{c}$ \\
\hline 5 & & $3 a$ & 40 & 40 & 93 \\
\hline 6 & & $3 b$ & 60 & 40 & 90 \\
\hline 7 & & $3 a$ & 60 & 40 & $93(88)^{c}$ \\
\hline 8 & & $3 a$ & 60 & 40 & 90 \\
\hline 9 & & $3 a$ & 60 & 25 & 100 \\
\hline 10 & & $3 b$ & 60 & 30 & $98(95)^{c}$ \\
\hline 11 & & $3 a$ & 40 & 30 & 95 \\
\hline 12 & & $3 a$ & 60 & 35 & 98 \\
\hline
\end{tabular}



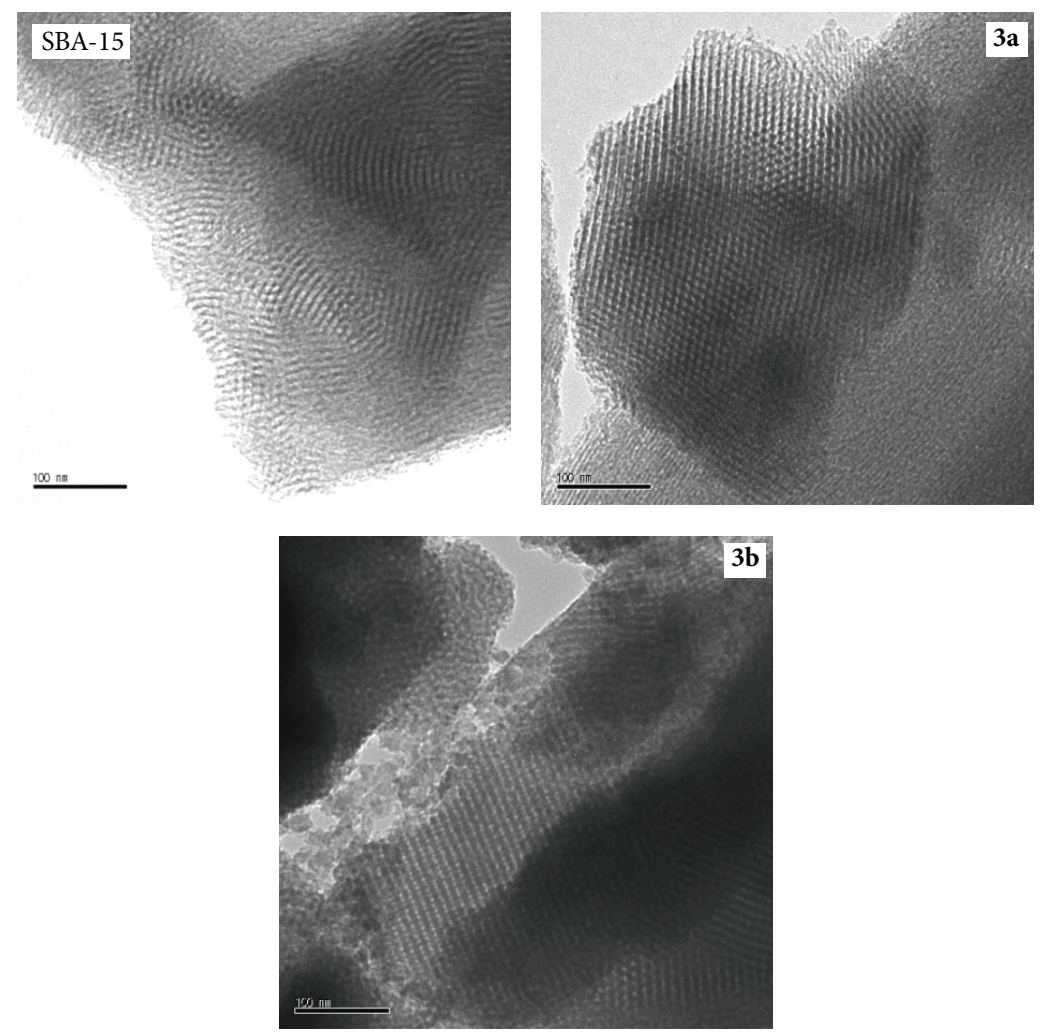

Figure 1: TEM images of parent SBA-15- and SBA-15-supported ligands $\mathbf{3} \mathbf{a}$ and $\mathbf{3 b}$.

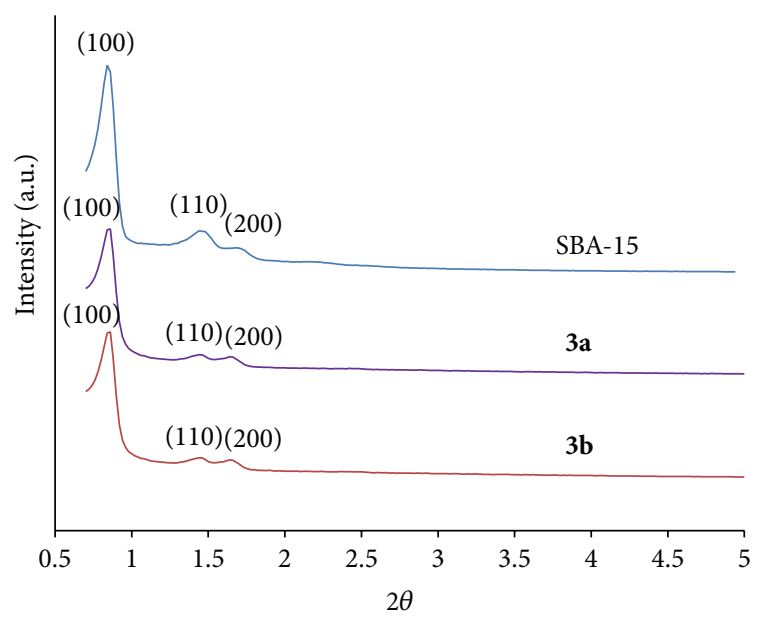

Figure 2: XRD pattern of modified SBA-15.

3). When the MW power was further decreased to 50$40 \mathrm{~W}$, the conversion was also decreased (entries 4,5 ). The propiophenone and $\alpha$-tetralone were smoothly converted into the corresponding alcohol with excellent yield (entries $7,8)$.

Recently, Baruwati et al. [31] reported magnetically recoverable supported ruthenium catalyzed transfer hydrogenation of carbonyl compounds in isopropanol at $100^{\circ} \mathrm{C}$ under microwave irradiation conditions. In this study, we performed hydrogen transfer reaction in pure water under

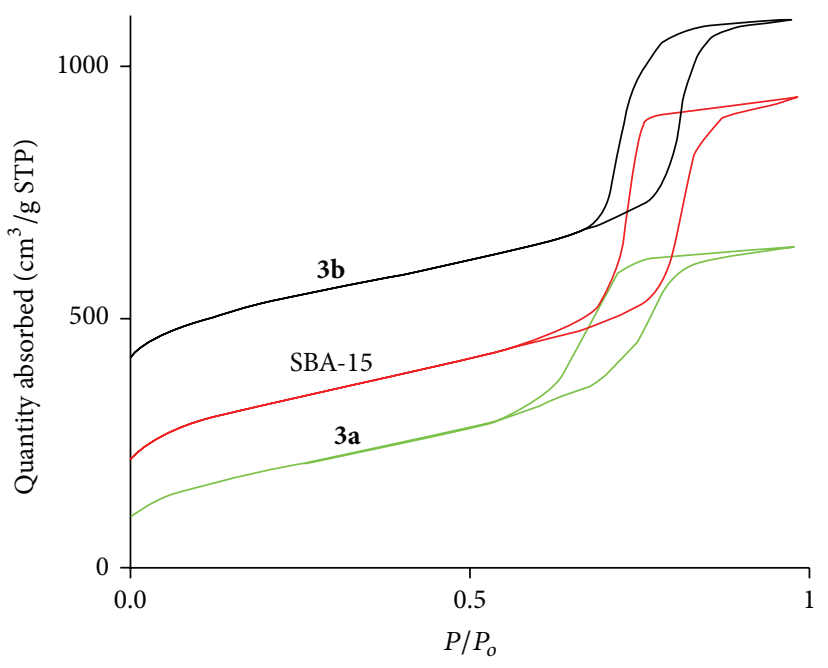

FIGURE 3: Nitrogen adsorption-desorption isotherms.

mild reaction condition, which is safer, more economical, more convenient, and greener for industrial applications.

Finally, we examined the transfer hydrogen reaction of 3chloroacetophenone and 2-acetylnaphthalene substrates and excellent results were obtained under the same microwave irradiation conditions (entries 9-12). The MW-assisted reaction reached completion with quantitative conversion within 


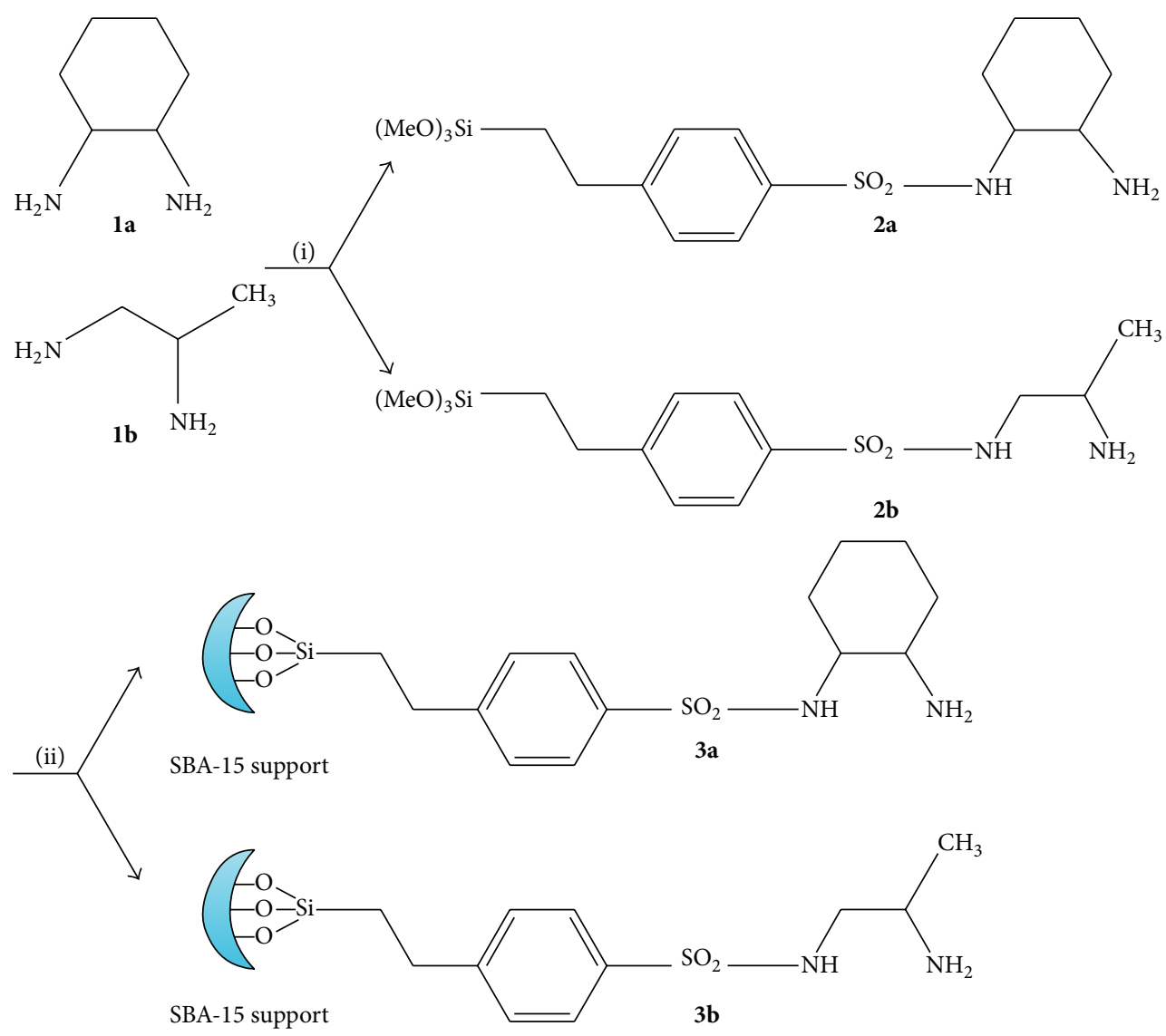

Scheme 1: Preparation of the SBA-15-supported $N$-sulfonyldiamine 3. (i) 2-(4-Chlorosulfonylphenyl)ethyltrimethoxysilane, triethylamine, $\mathrm{CH}_{2} \mathrm{Cl}_{2}-10^{\circ} \mathrm{C}$ to room temperature, $2 \mathrm{~h}$; (ii) SBA- 15 , toluene, $105^{\circ} \mathrm{C}, 18 \mathrm{~h}$.

25 min with a TOF of up to $245 \mathrm{~h}^{-1}$ in presence of SBA-15supported ligand $\mathbf{3 a}$ (entry 9). The conversions seemed to be insensitive to substituent or structure of the substrates. It is noteworthy that the $\mathrm{Ru}$ catalyst could be reused with consistent catalytic activity (entry 3). The SBA-15-supported ligand $\mathbf{3 b}$ also showed similar catalytic activity to ligand $\mathbf{3 a}$ under similar reaction conditions (entries 6, 10).

\section{Conclusion}

We have prepared recyclable SBA-15-supported $N$-sulfonyl1,2-diamine ligands from 1,2-diaminocyclohexane and 1,2diaminopropane. Microwave-assisted heating was employed for heterogeneous $\mathrm{Ru}$-catalyzed transfer hydrogenation of ketones. The immobilized $\mathrm{N}$-sulfonyldiamine $\mathrm{Ru}$-complex showed extremely high catalytic activity (TOF $245 \mathrm{~h}^{-1}$ ) under microwave heating condition. Moreover, the catalyst could be reused without significant loss of activity.

\section{Conflict of Interests}

All authors declare that this paper does not have any content with conflict of interests.

\section{Acknowledgment}

The authors acknowledge the Universiti Malaya Fund no. RP005A-13AET to Md. Eaqub Ali.

\section{References}

[1] E. N. Jacobsen, A. Pfaltz, and H. Yamamoto, Eds., Comprehensive Asymmetric Catalysis, Springer, Berlin, Germany, 1999.

[2] M. J. Palmer and M. Wills, "Asymmetric transfer hydrogenation of $\mathrm{C}=\mathrm{O}$ and $\mathrm{C}=\mathrm{N}$ bonds," Tetrahedron Asymmetry, vol. 10, no. 11, pp. 2045-2061, 1999.

[3] S. Gladiali and E. Alberico, "Asymmetric transfer hydrogenation: chiral ligands and applications," Chemical Society Reviews, vol. 35, no. 3, pp. 226-236, 2006.

[4] W. Baratta, J. Schütz, E. Herdtweck, W. A. Herrmann, and P. Rigo, "Fast transfer hydrogenation using a highly active orthometalated heterocyclic carbene ruthenium catalyst," Journal of Organometallic Chemistry, vol. 690, no. 24-25, pp. 55705575, 2005.

[5] R. Noyori and S. Hashiguchi, "Asymmetric transfer hydrogenation catalyzed by chiral ruthenium complexes," Accounts of Chemical Research, vol. 30, no. 2, pp. 97-102, 1997.

[6] R. A. W. Johnstone, A. H. Wilby, and I. D. Entwistle, "Heterogeneous catalytic transfer hydrogenation and its relation to other methods for reduction of organic compounds," Chemical Reviews, vol. 85, no. 2, pp. 129-170, 1985. 
[7] S. Horn, C. Gandolfi, and M. Albrecht, "Transfer hydrogenation of ketones and activated olefins using chelating NHC ruthenium complexes," European Journal of Inorganic Chemistry, vol. 18, no. 2, pp. 2863-2868, 2011.

[8] W. Ye, M. Zhao, and Z. Yu, "Ruthenium(II) pyrazolyl-pyridyloxazolinyl complex catalysts for the asymmetric transfer hydrogenation of ketones," Chemistry, vol. 18, no. 35, pp. 10843-10846, 2012.

[9] M. D. Le Page and B. R. James, "Nickel bromide as a hydrogen transfer catalyst," Chemical Communications, no. 17, pp. 16471648, 2000.

[10] R. Kadyrov and T. H. Riermeier, "Highly enantioselective hydrogen-transfer reductive amination: catalytic asymmetric synthesis of primary amines," Angewandte Chemie, vol. 115, no. 44, pp. 5630-5632, 2003.

[11] P. N. Liu, P. M. Gu, F. Wang, and Y. Q. Tu, "Efficient heterogeneous asymmetric transfer hydrogenation of ketones using highly recyclable and accessible silica-immobilized Ru-TsDPEN catalysts," Organic Letters, vol. 6, no. 2, pp. 169-172, 2004.

[12] C. Saluzzo and M. Lamaire, "Homogeneous-supported catalysts for enantioselective hydrogenation and hydrogen transfer reduction," Advanced Synthesis \& Catalysis, vol. 344, no. 9, pp. 915-928, 2002.

[13] X. Li, X. Wu, W. Chen, E. F. Hancock, F. King, and J. Xiao, "Asymmetric transfer hydrogenation in water with a supported Noyori-Ikariya catalyst," Organic Letters, vol. 6, no. 19, pp. 33213324, 2004.

[14] Y.-C. Chen, T.-F. Wu, J.-G. Deng et al., "Dendritic catalysts for asymmetric transfer hydrogenation," Chemical Communications, no. 16, pp. 1488-1489, 2001.

[15] Y.-C. Chen, T.-F. Wu, J.-G. Deng et al., "Multiple dendritic catalysts for asymmetric transfer hydrogenation," Journal of Organic Chemistry, vol. 67, no. 15, pp. 5301-5306, 2002.

[16] Y.-C. Chen, T.-F. Wu, L. Jiang et al., "Synthesis of dendritic catalysts and application in asymmetric transfer hydrogenation," Journal of Organic Chemistry, vol. 70, no. 3, pp. 1006-1010, 2005.

[17] P. N. Liu, J. G. Deng, Y. Q. Tu, and S. H. Wang, "Highly efficient and recyclable heterogeneous asymmetric transfer hydrogenation of ketones in water," Chemical Communications, vol. 10, no. 18, pp. 2070-2071, 2004.

[18] D. J. Bayston, C. B. Travers, and M. E. C. Polywka, "Synthesis and evaluation of a chiral heterogeneous transfer hydrogenation catalyst," Tetrahedron Asymmetry, vol. 9, no. 12, pp. 2015-2018, 1998.

[19] R. Ter Halle, E. Schulz, and M. Lemaire, "Heterogeneous enantioselective catalytic reduction of ketones," Synlett, vol. 1997, no. 11, pp. 1257-1258, 1997.

[20] T. J. Geldbach and P. J. Dyson, "A versatile ruthenium precursor for biphasic catalysis and its application in ionic liquid biphasic transfer hydrogenation: conventional vs task-specific catalysts," Journal of the American Chemical Society, vol. 126, no. 26, pp. 8114-8115, 2004.

[21] M. J. Gracia, J. M. Campelo, E. Losada, R. Luque, J. M. Marinas, and A. A. Romero, "Microwave-assisted versatile hydrogenation of carbonyl compounds using supported metal nanoparticles," Organic and Biomolecular Chemistry, vol. 7, no. 23, pp. 48214824, 2009.

[22] A. P. Wright and M. E. Davies, "Design and preparation of organic-inorganic hybrid catalysts," Chemical Reviews, vol. 102, no. 10 , pp. 3589-3614, 2002.
[23] J. Y. Ying, C. P. Mehnert, and M. S. Wong, "Synthesis and applications of supramolecular-templated mesoporous materials," Angewandte Chemie International Edition, vol. 38, pp. 5677, 1999.

[24] D. Zhao, Q. Huo, J. Feng, B. F. Chemlka, and G. D. Stucky, "Nonionic triblock and star diblock copolymer and oligomeric surfactant syntheses of highly ordered, hydrothermally stable, mesoporous silica structures," Journal of the American Chemical Society, vol. 120, pp. 6024-6036, 1998.

[25] N. E. Leadbeater and M. Marco, "Preparation of polymersupported ligands and metal complexes for use in catalysis," Chemical Reviews, vol. 102, no. 10, pp. 3217-3274, 2002.

[26] C. O. Kappe, "Controlled microwave heating in modern organic synthesis," Angewandte Chemie International Edition, vol. 43, no. 46, pp. 6250-6284, 2004.

[27] T. Marimuthu and H. B. Friedrich, "Microwave-assisted transfer hydrogenation of ketones by $\mathrm{Ru}$ (xantphos) arene complexes," ChemCatChem, vol. 4, no. 12, pp. 2090-2095, 2012.

[28] A. Bengtson, A. Hallberg, and M. Larhed, "Fast synthesis of aryl triflates with controlled microwave heating," Organic Letters, vol. 4, no. 7, pp. 1231-1233, 2002.

[29] S. Brunauer, P. H. Emmett, and E. Teller, "Adsorption of gases in multimolecular layers," Journal of the American Chemical Society, vol. 60, no. 2, pp. 309-319, 1938.

[30] W. W. Lukens Jr., P. Schmidt-Winkel, D. Zhao, J. Feng, and G. D. Stucky, "Evaluating pore sizes in mesoporous materials: a simplified standard adsorption method and a simplified Broekhoff-de Boer method," Langmuir, vol. 15, no. 16, pp. 54035409, 1999.

[31] B. Baruwati, V. Polshettiwar, and R. S. Varma, "Magnetically recoverable supported ruthenium catalyst for hydrogenation of alkynes and transfer hydrogenation of carbonyl compounds," Tetrahedron Letters, vol. 50, no. 11, pp. 1215-1218, 2009. 

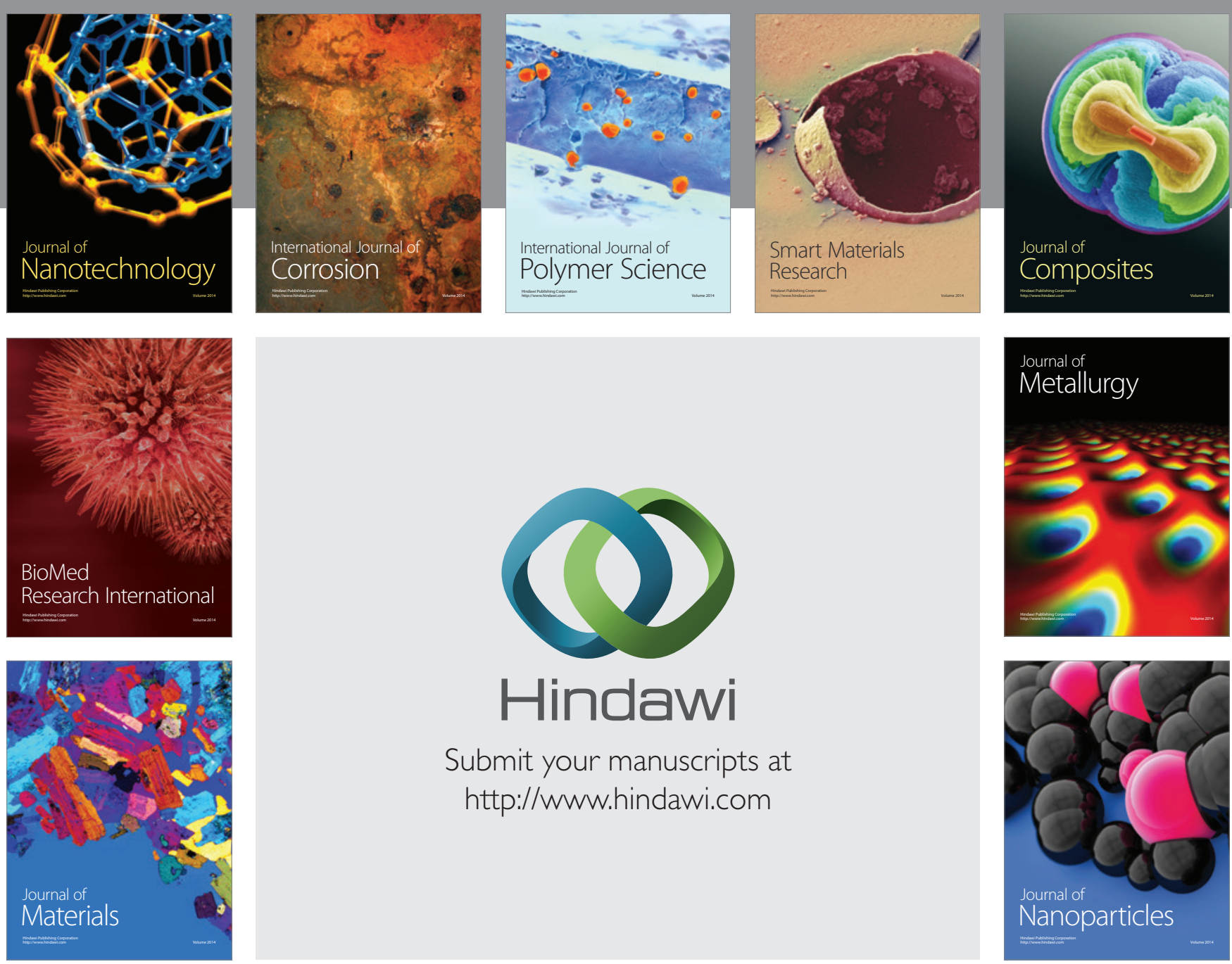

Submit your manuscripts at http://www.hindawi.com
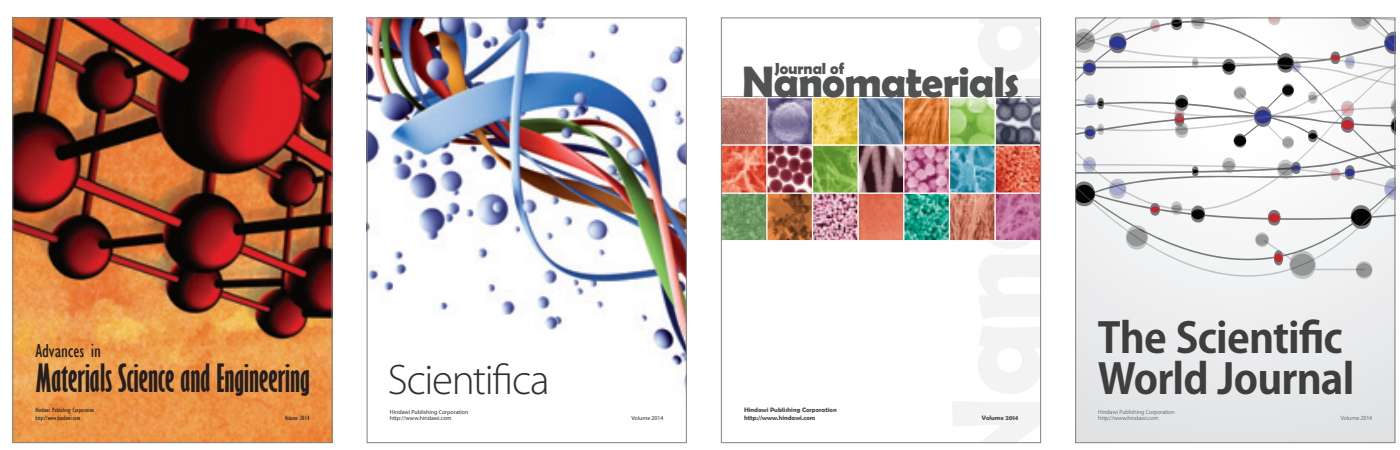

\section{The Scientific World Journal}
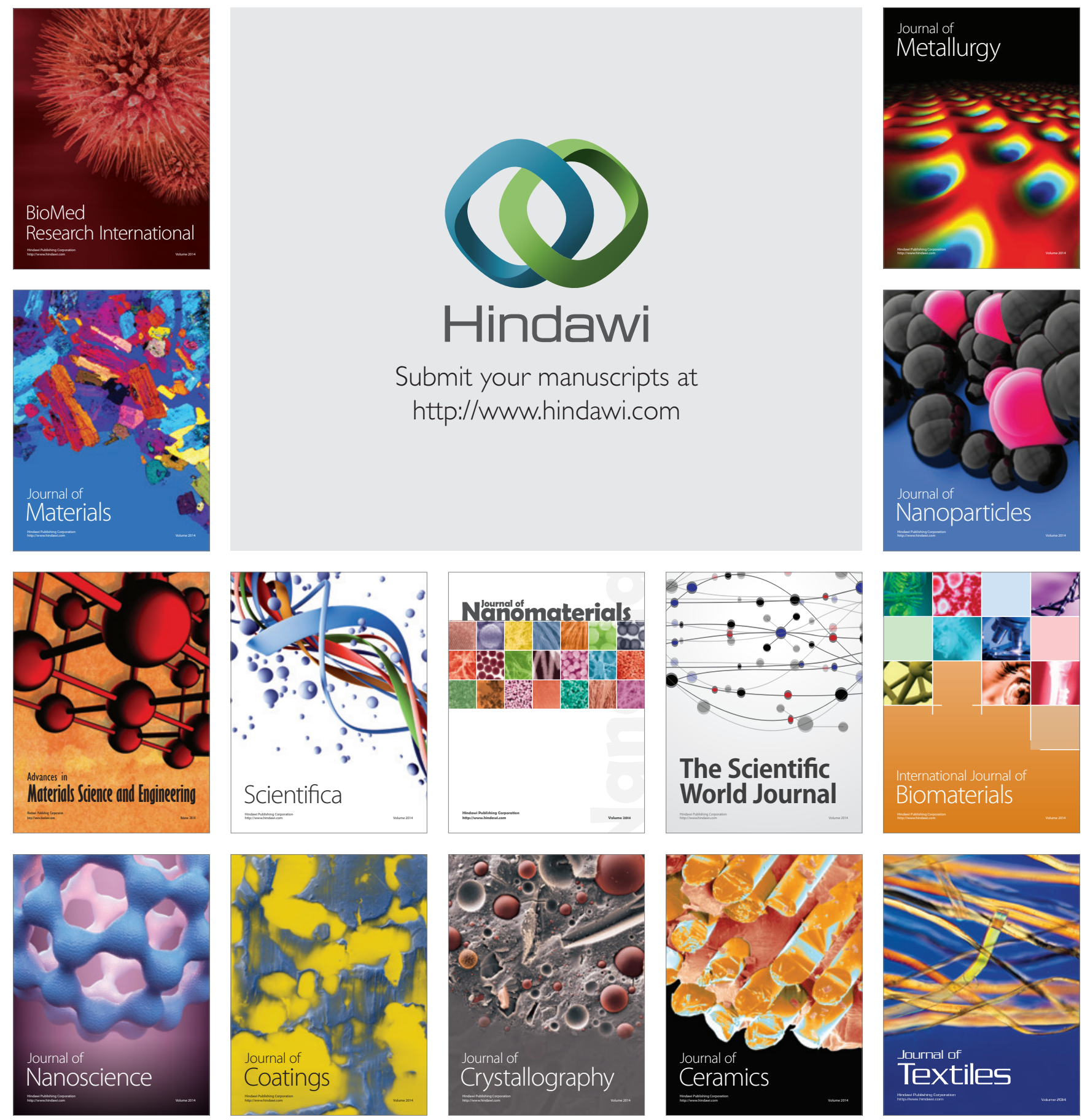